\title{
The emotional coaching model: quantitative and qualitative research into relationships, communication and decisions in physical and sports rehabilitation
}

\author{
STEFANO RESPIZZI ${ }^{1}$, ELISABETTA COVELLI ${ }^{2}$ \\ ${ }^{1}$ Department of Rehabilitation, IRCCS Humanitas Research Hospital, Rozzano, Milan, Italy \\ ${ }^{2}$ Meravigli Medical Center, Milan, Italy
}

\begin{abstract}
The emotional coaching model uses quantitative and qualitative elements to demonstrate some assumptions relevant to new methods of treatment in physical rehabilitation, considering emotional, cognitive and behavioral aspects in patients, whether or not they are sportsmen.

Through quantitative tools (Tampa Kinesiophobia Scale, Emotional Interview Test, Previous Re-Injury Test, and reports on test scores) and qualitative tools (training contracts and relationships of emotional alliance or "contagion"), we investigate initial assumptions regarding: the presence of a cognitive and emotional mental state of impasse in patients at the beginning of the rehabilitation pathway; the curative value of the emotional alliance or "emotional contagion" relationship between healthcare provider and patient; the link between the patient's pathology and type of contact with his own body and emotions; analysis of the psychosocial variables for the prediction of possible cases of re-injury for patients who have undergone or are afraid to undergo reconstruction of the anterior cruciate ligament (ACL).

Although this approach is still in the experimental stage, the scores of the administered tests show the possibility of integrating quantitative and qualitative tools to investigate and develop a patient's physical,
\end{abstract}

\footnotetext{
Corresponding Author:

Stefano Respizzi, MD

Department of Rehabilitation, IRCCS Humanitas

Research Hospital

Via Manzoni 113, 20089 Rozzano (MI), Italy

E-mail: dott.respizzi@gmail.com
}

mental and emotional resources during the course of his rehabilitation. Furthermore, it seems possible to identify many elements characterizing patients likely to undergo episodes of re-injury or to withdraw totally from sporting activity. In particular, such patients are competitive athletes, who fear or have previously undergone ACL reconstruction.

The theories referred to (the transactional analysis theory, self-determination theory) and the tools used demonstrate the usefulness of continuing this research in order to build a shared coaching model treatment aimed at all patients, sportspeople or otherwise, which is not only physical but also emotional, cognitive and behavioral.

Keywords: test, emotions, alliance, impasse, coaching, re-injury.

\section{Theoretical references from philosophy, medicine and psychology}

Transactional analysis is a psychological theory that, arising in the United States in the 1960s, has since spread worldwide. Its founder was Eric Berne (19101970), a son of Jewish immigrants, of Austrian origin, who was born in Canada and lived in the USA until his death. He was a student of the neo-Freudian psychologist and psychoanalyst Erik Eriksson, from whom he subsequently diverged, developing his own original insights.

As with any Western psychological theory, the theoretical foundation of transactional analysis is the existentialist phenomenology of Husserl and Heidegger that started to appear in Europe in the early decades 
of the 1900s. Their theoretical principles concern the centrality of the patient and respect for the patient on the part of the physician. The idea, at the time revolutionary, is that the patient knows his own needs and the doctor is competent on his own technical skills (1). Thus, based on mutual respect, an "intersubjective relationship" becomes established. This means that "the two subjects exist when they perceive each other" (2). Obviously, here the underlying existence is not ontological but phenomenological; the subjects exist as "phenomena", as "experiences that will show on the outside, becoming visible and audible, in fact perceived". On the basis of these theoretical assumptions, the "care relationship" is necessarily equal and reciprocal, despite the differences in roles and responsibilities. The operator is no longer merely an expression of knowledge and techniques but one of the two poles of a relationship, mutually perceived as curative. The hypothesis is, in fact, that an intersubjective relationship can create that "warm spark" or "emotional alliance" that stimulates the patient to come out of his isolation and to take an active and effective part in his healing process (3).

It is probable that patients at the start of a pathway of physical and sports rehabilitation are, in most cases, in a pathological mental state called "impasse" or "contamination". In this state, the patient believes that he is thinking, feeling and acting in a rational way, appropriate to his own situation and to the surrounding environment; instead, he is influenced by factors related to his childhood: by prejudices, generalizations and world views, inherited from his parental figures, and by phobias, desires and illusions not related to reality, to the here and now.

The normal personality structure, according to the transactional analysis theory, is characterized by three phenomenological states, which are joined with each other (Fig. 1). Instead, in the pathological personality structure, i.e. the state of impasse, some parts of the personality "invade" the boundaries of the central one (Fig. 2). The rational adult is able to listen to himself and others, responding appropriately to the existing "stimula" (4).

During the state of impasse, for example, the patient imagines his disease having a catastrophic course, or expects magic solutions, or feels persecuted by family members or doctors. The common element, in all these cases, is that the patient has shifted responsibility for the

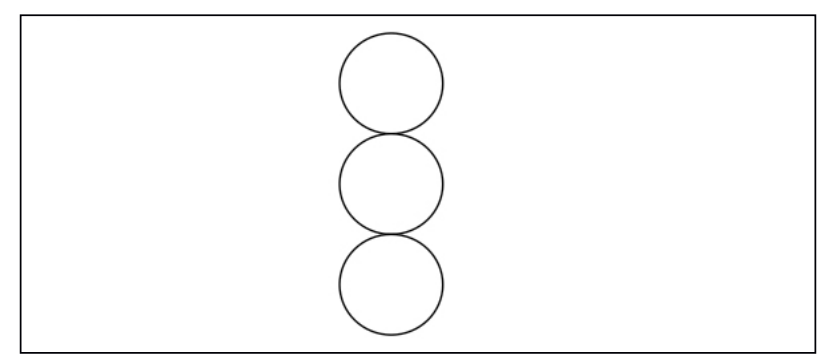

Fig. 1. NORMAL PERSONALITY STRUCTURE

The Figure shows the normal personality structure, according to the transactional analysis theory, founded by the psychiatrist Eric Berne.

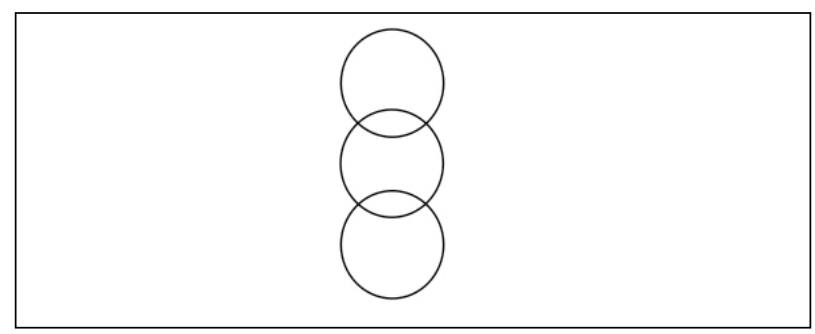

Fig. 2. PATHOLOGICAL PERSONALITY STRUCTURE

The Figure shows the pathological personality structure, called "Impasse", according to the transactional analysis theory.

outcome of his own rehabilitation process to external entities.

Other times, however, the patient perceives the disease as a punishment caused by his own mistakes, with the result that the sense of personal responsibility becomes an intolerable and lonely burden.

It must be remembered a patient in the impasse state is cognitively confused; he will often fail to understand or remember the doctor's directions, even when they are expressed in clear and simple language.

An additional element is the presence of emotional confusion, as a result of which personal feelings are hardly recognized. It is as though the pain of the body "masks" all other emotions, with the result that anger, sadness and fear are mixed together.

In the presence of a patient in a state of cognitive and emotional impasse, what seems clear to the outside observer is his behavior, which is usually that of one who is unable to solve current problems. This behavior is called "racketeering". For example, the patient tends to isolate himself through stubborn silences, forced separations and poor concentration. Other times, the patient appears very "agitated" for no apparent reason, displaying forms of hyperkinesia (where this is possi- 
ble), risk attitudes, logorrhea, poor concentration and poor motor coordination; usually, after these prolonged episodes, the existing disease get worse or a new one has onset. According to the transactional analysis theory, the emotional elements that influence these behaviors are several. In Western civilization, emotions were, for a long time, regarded as an obstacle to the achievement of desired objectives or as a sign of weakness of character. Only certain emotions were tolerated in social and family settings. For example, in the last century, anger was an acceptable emotion for the male gender, whilst sadness and melancholy were deemed acceptable largely as female emotions. Thus, whole generations were educated, in particular, to accept and recognize these two emotions, and to hide the others (5).

According to the latest neurological (6), anthropological (7) and psychological research (8), authentic human emotions are very similar to those of primates and can be reduced to a short list: surprise, interest, disgust, fear, anger, sadness, joy, in addition to the primary physical sensations: thirst, hunger, sleep, fatigue, physical pain (9). Each of these emotions, when actually recognized by the subject, is an important energy and information resource. Fear can be transformed into caution, anger into determination, sadness into awareness. Joy is a state of peacefulness, while pain, both inner and physical, warns us that we need to change something in ourselves, in our body or in our life.

In a given period of time, different authentic emotions can coexist in the same person but only one determines his next behavior.

In general, authentic emotions produce a natural movement towards the well-being of the individual. Instead, in the impasse state, this natural movement is blocked or deflected into ineffective or harmful behaviors. In these cases, the intersubjective relationship that is established between the patient and network of operators around him (doctors, physiotherapists, nurses, psychologists, analysts) itself becomes a care instrument.

\section{Qualitative and quantitative tools in the relationship between healthcare operator and patient}

According to the theoretical assumptions stated above, the healthcare relationship is effective when there is a mutual exchange between two or more sub- jects. This relationship may be seen as a qualitative tool both for research and rehabilitation treatment purposes.

According to Freud, there is not only "transfert", i.e. the transfert of affect from the patient to the operator, but also "contra-transfert", a reverse and equal transfert from the operator to the patient. Thus, not only does the patient see and recognize himself in his doctor as though the latter were a benevolent mirror - this experience is usually called the "mirror effect" - but the emotional transfert is mutual and equal.

We think that this can be considered a form of "emotional contagion". In fact, if human emotions are indeed actually few and elementary, as the latest neurological and anthropological findings indicate, then it is possible to hypothesize that, within significant relationships such as those formed in the care setting, the emotions involved are more than similar, indeed identical and specular. It may possibly be hypothesized that in the patient and the healthcare professional two very similar (in quality, not quantity) emotional processes take place. This is a hypothetical interpretation of the rehabilitation process, but it seeks to highlight the connection between body, emotions, thoughts and behaviors, in both the poles of the intersubjective relationship.

The diagrams "The patient" and "The operator" (Figs. 3, 4) show a possible rehabilitation pathway viewed from both the patient and the operator's point of view: along this pathway, we propose several episodes of pain, i.e. physical pain experienced by the patient and observed by the operator, which stimulate, in both subjects, the same authentic emotions but with

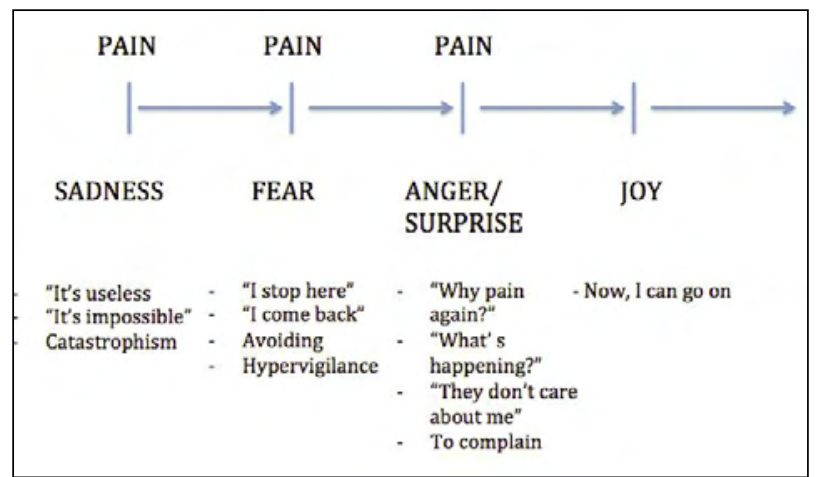

Fig. 3. THE PATIENT

The diagram shows, from the patient's perspective, a possible "emotional course" during the rehabilitation pathway. 


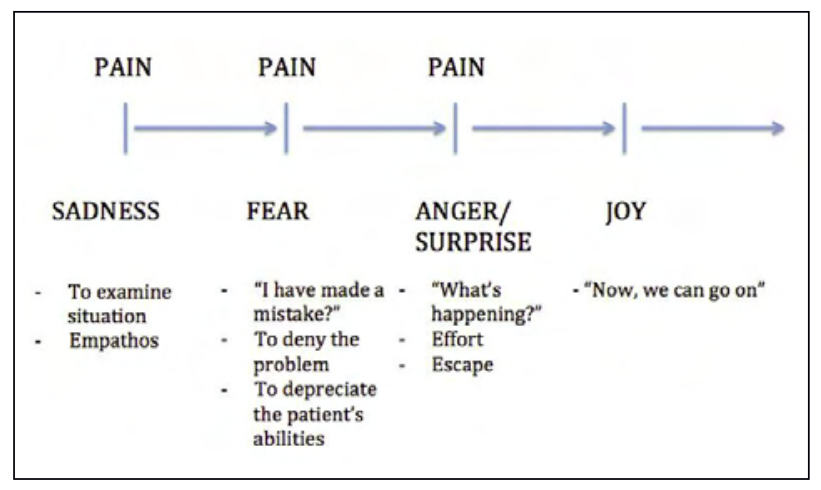

Fig. 4. THE OPERATOR

The diagram shows a possible "emotional course" from the operator's perspective. It is very similar, in quality but not in quantity, to the patient's one.

different intensity. From our observations, it is possible to imagine that, in the first part of the rehabilitation pathway, the patient's physical pain is accentuated and the degree of disability is quite high. According to our hypothesis, this kind of situation leads the patient into the state of impasse; he will probably be sad and discouraged, and in need of emphatic support. Subsequent episodes of physical pain, which may occur during a course of rehabilitation, stimulate emotions such as fear and anger that produce thoughts and actions in both subjects.

The diagrams show that the two pathways (the patient's and the operator's) are very similar in terms of the emotions felt, while they are different in terms of the episodes, "stimula" and quantity. In fact, "contra-transfert" feelings are usually less intense than the corresponding feelings experienced by the patient.

These similarities and differences allow the operator to enter into and remain in an empathic alliance with the patient while remaining lucid enough to listen to himself and while observing the patient, both factors that enable the doctor to improve his skills and strategies. Thus, emotions provide the operator with information allowing him to define the boundaries of his own role and the intervention required.

In addition to the emotional alliance, another aspect of the intersubjective relationship is "communication" which can be a good tool for stimulating and awakening the patient in the state of impasse. In this regard, there exist various "decontamination" techniques; although these can be used by only a few professionals, they are tools that facilitate an effective mode of communication. "Contract training", for example, is the term we use to refer to the use of both verbal and written agreements between the operator and the patient. Together, the two subjects in the relationship can define the times, methods and objectives of the rehabilitation process. This approach can be used to investigate expectations, motivation and difficulties. By explaining some of these elements, and by giving "structure" to the rehabilitation program, which is often invaded by tacit knowledge, magical expectations and catastrophic prejudices, we can encourage autonomy and responsibility in the patient.

In patients from sports settings, e.g. patients requiring rehabilitation after accidents during training or competitions, the network surrounding the patient may be more extensive than in the case of patients who are not sportspeople. For example, these patients may be assisted by coaches, sports clubs and teammates, in addition to several healthcare professionals. In such circumstances, when the patient is in the middle of a web of complex relations, only clear communication between the different stakeholders can help make the rehabilitation process effective and unequivocal. In these cases, it is useful to stipulate training pacts, called "multiple contracts", with all the stakeholders involved (10). In this way, the expectations of the patient, the health center and the sports club can be made explicit and shared in order to allow a faster rehabilitation process.

In conducting an experimental project on the "emotional coaching model", we have used several quantitative tools in addition to training pacts. One is the Tampa Scale for Kinesiophobia (TSK), suitable for measuring the level of fear of movement and physical pain $(11,12)$. We use the complete version of the TSK, because the short one needs further studies to prove its definitive efficiency (13).

After the TSK, a second experimental test, called the "emotional interview", is administered. Its aim is to assess the resources that the patient will be able to implement during the course of his rehabilitation, for example: whether he is capable of recognizing and using his own emotions, understanding the reality of his own physical situation, identifying his personal responsibility, and respecting the boundaries of roles and skills.

Finally, a further experimental test, called the "previous re-injury test", is administered; its objective is to 
define and record the psychosocial variables that can influence episodes of re-injury or abandonment of competitive sport in injured patients.

In the experimental stage, two/three individual interviews are conducted between the analyst and the patient, each lasting about an hour, allowing the presentation and administration of the tests and handing back of the final test scores. These interviews, conducted in a protective setting, are opportunities for the patient to disclose his difficulties and expectations, of which he may often be unaware. In this way, we can encourage development of the patient's emotional, cognitive and behavioral skills. Also, the rehabilitation course can be modified in order to further increase the chances of ultimate success. We have in fact noted that, with this approach, the attitude towards the rehabilitation process, both in the patient and the network around him, changes, often in the space of just a few weeks, becoming more conscious, active and confident.

Looking at the "TSK" in the light of the transactional analysis theory, we can see that it reveals "parental" prejudices and generalizations which may lead to phobic behavior such as catastrophism and superstition.

The "emotional interview", on the other hand, focuses on the "child" aspects of personality, such as emotions, contact with the body, relationships with doctors and operators. Low scores on these aspects detect possible phobic behaviors such as avoidance and hypervigilance. Moreover, this test seeks to identify and encourage the locus of control or sense of personal responsibility and the capacity to share fears and hopes during the rehabilitation process.

The "previous re-injury test" explores "parent", "adult" and "child" aspects of personality; for example:

- personal, family and social values and/or prejudices;

- the capacity to analyse oneself and reality; decisional, planning and relational skills;

- creative and pleasurable aspects related to sport and competition.

As explained earlier, the scores are returned, accompanied by reports, both to the referring physician and patient, after administering the tests. These reports indicate any verbal inconsistencies or behavioral, cognitive and emotional difficulties of the patient. In this way, the analysis of quantitative data becomes an opportunity to establish, between the analyst and the patient, the initial qualitative emotional alliance, useful for a possible emotional coaching pathway (10 meetings) (14).

The proposed model also has the aim of responding to needs arising in recent research conducted in the US, Canada, Great Britain and Scandinavia, according to which only $19 \%$ of patients and athletes claim that their emotional needs during the rehabilitation course were met by adequate psychological support (15).

In summary, the "emotional coaching model" aims, through quantitative and qualitative tools, to test hypotheses and, with the patient, reach a series of objectives:

- recognition and use of emotions by the patient as positive resources for healing;

- improvement of the ability to "feel" the body, identifying "stimula" useful for healing;

- respect for the boundaries of roles, skills and responsibilities so that the patient becomes an active subject in his own rehabilitation pathway;

- recollection and achievement of cognitive understanding of the trauma or injury suffered by the patient, to allow the identification of logical links between causes and effects;

- better communication between patient and healthcare operators;

- use of the rehabilitation pathway as an opportunity to improve the patient's knowledge of himself and his future professional plans;

- identification of the personal, family and social factors that influence the "decision" to undergo reconstruction of the anterior cruciate ligament (ACL) and/or to return to competitive activity. Our hypothesis is that the more authentic this "decision" is, the less will be the risk of subsequent re-injury;

- verification of the validity of the hypothesis that, in some cases, the factors that lead to the first injury are similar to those that lead to the second injury. Was this hypothesis found to be correct, it would be possible to implement effective prevention interventions.

\section{The emotional coaching model: a process of self-awareness and physical rehabilitation}

The "emotional coaching model" is based on all that has been set out above: the impasse concept, the importance of a significant emotional alliance bet- 
ween patient and operator, the use of effective tools and communication techniques, the recognition and use of authentic emotions, support during decisionmaking and analysis of decisions taken by the patient or patient-athlete.

The "emotional coaching model" presents two possible rehabilitation pathways (Fig. 5): one fails and the other leads to healing or improvement of the patient. He regains a level of autonomy, mobility and mental health that is equal to or greater than that which he had at the time of the accident or onset of the pathology.

We believe that the "emotional coaching model", albeit still in the experimental stage, demonstrates that the physical rehabilitation of a patient goes hand in hand with an inner process of emotional, communicative and relational awareness, that is equally therapeutic. The mind and body appear indisputably connected and interdependent (16).

From the interviews we have conducted and the tests we have administered it seems that, for many patients, the treatment period becomes a process of steadily increasing self-awareness in which the body and certain parts of the "self", previously unknown or forgotten, reappear and demand attention. Body language acquires a hitherto unknown meaning, and is to be listened to

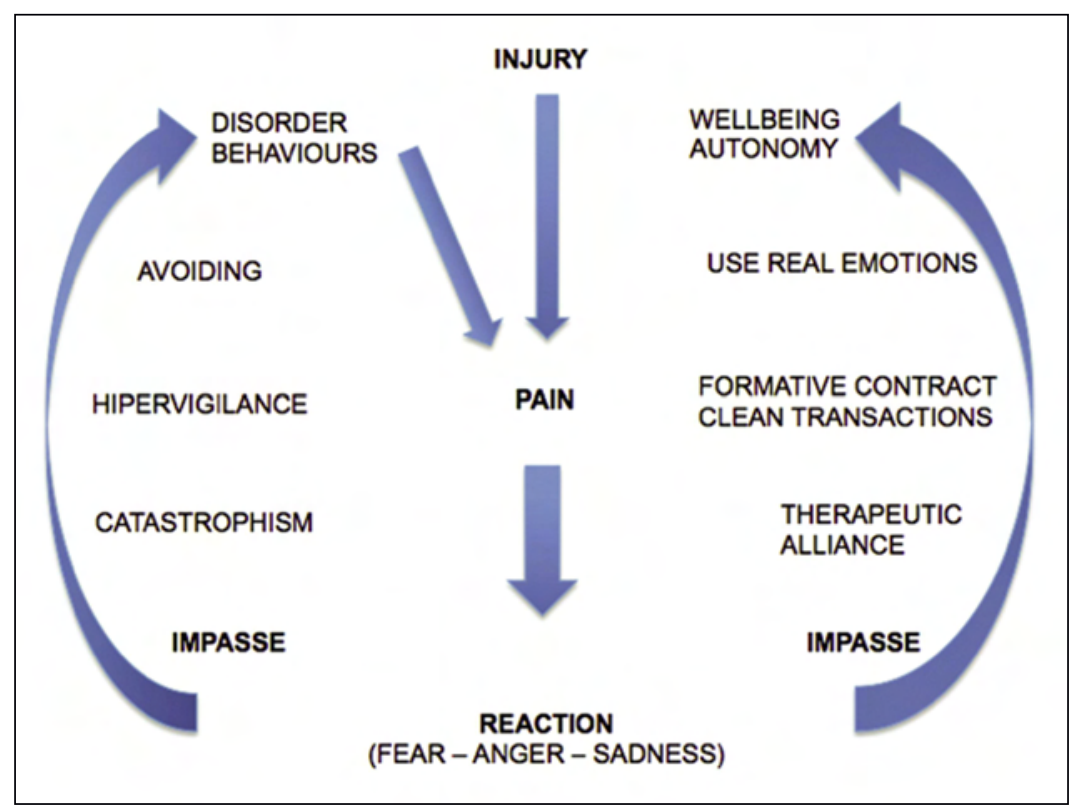

Fig. 5. THE EMOTIONAL COACHING MODEL

The diagram shows two possible rehabilitation pathways: one fails and the other shows the patient's improvement achieved through use of emotional coaching tools. and interpreted with attention and "love". In this way, the body assumes characteristics more similar to those of the "self", so as not to be considered and treated as a machine able to accept or to fight against time, commitments, trends and society needs. The body has its own emotions and its own interiority, and these are turned into potential sources of positive energy.

In professional sportsmen, the body assumes a very important meaning, as the means of personal and professional success. Indeed, the social and personal identity of a sportsman is more closely connected with the body than is normally the case (17).

Accordingly, a sportsman's body can be subjected to intensive training schedules and expected to perform to high standards, and this can be a source of anxiety. In some cases, an accident, on or off the field, seems to be the result of an unconscious desire, on the part of the player, to stop and to reflect on himself and his own future. Here, emotions such as fear, anger and sadness are unleashed in a chaotic way, which is reflected in apparently contradictory behaviors, for example a footballer may constantly demand to return to the field for regular workouts, only to experience a sense of panic on setting foot on the pitch.

Some patients involved in competitive sport have been administered both the "emotional interview test" and the "previous reinjury test"; the rehabilitation program has thus become the opportunity to find a harmonious balance between deep personal needs and realistic professional expectations. In these cases, it is possible to say that sports rehabilitation is successful not only when the patient recovers the ability to participate in sport at the same level as prior to the accident, but also when he is able to use his talents with greater awareness, determination and caution. Thus, the integration of body and emotions produces a higher level of sports performances than the period preceding the accident (18).

The test batteries and questionnaires thus far administered demonstrate, although this approach is still in the experimental stage, the hypotheses so far established (Tab. 1). 
Recognition and the positive use of emotions seem to radically change the patient's attitude to the rehabilitation period and therefore the way it is experienced and its ultimate success.

In addition, psychosocial variables, identified in the "previous re-injury test", appear to be effective in predicting the rehabilitation course and, above all, the patient's stated "decision", i.e. to return or not to competitive sport after the ACL reconstruction, and in establishing the level of awareness and realism accompanying this decision.

Thus, both the tests and the intersubjective relationship become the tools not only of medical and psychological but also social research.

For example, identification of the risk factors and prevention strategies for patients who have undergone ACL reconstruction can have important economic and health implications. Indeed, we recall that in the US the cost calculated for injuries of this type is about $\$ 1$ billion (19).

In addition, in the US and Northern Europe, only 60\% of athletes return to racing after a first ACL operation; while $40 \%$ "decide" to focus on other activities, considering their sport a hobby or, even, a memory. Thus, identifing variables that influence this "decision", which is not only physical but also mental and social, assumes scientific and political importance (20).

The "previous re-injury test" tries to reach this goal, considering both the transactional analysis theory and the self-determination theory that investigates the social conditions as facilitators of the healing process (21).

As explained earlier, our hypotheses are two:

- the variables that lead the athlete to injury are similar to those that affect the "decision" both to reconstruct the ACL and to return to competitive sports activity; - the more authentic the patient's "decision" is (congruent with external reality and own emotions), the lower his likelihood of experiencing a re-injury or of totally withdrawing from his sport.

It would appear that both assumptions have been satisfactorily borne out by the results of the "previous reinjury test" administered to date, although more data are needed, also on follow up. We recall that this test was constructed only recently, therefore it has been administered to only a small number of patients. However, the test seems to identify points for reflection that are congruent with the results of the latest research.
For example, it seems that young male students, without social and family problems, are those who return to competitive sport with greater success (22). In addition, a large body of literature shows that the risk of re-injury seems to be inversely proportional to the fear of movement and a negative view, sometimes catastrophizing, of rehabilitation and sport. Therefore, the rehabilitation period becomes a valuable opportunity for the injured athlete, allowing him not only to restore knee function but also to recover and develop confidence in himself, in the future and in sport (23-26).

Some psychological and behavioral strategies (for example techniques in which the subject is required to prefigure himself and the future, in addition to techniques designed to encourage contact with one's body and emotions) seem to significantly develop the ability to control and positively use the fear of re-injury, increasing the chances of successful rehabilitation and a conscious return to sporting activity at a level equal to or greater than the level prior to injury (27).

Extensive administration of the instruments mentioned herein may offer further verification of our hypotheses and new "stimula" for research.

Instead, from administration of the "emotional interview test", it seems that for other types of clinical cases - we refer to people who practise just a little sport -, it is possible to hypothesize that pathologies such as low back, pubic or cervical pain, which are physical problems not related to accidents or evident traumas, are a direct expression of distress, almost constituting a behavior. Indeed, these physical disabilities can be considered the body's response - primitive and ineffective, but nevertheless existing - to some deep psychological distress.

Here, the "soma", in the face of cognitive and emotional confusion, seems to "cry out" its pain. In these particular cases, we can also hypothesize an unconscious and unintentional alteration of physical pain perception. The topic of somatization is a very broad one but it deserves further study in order to identify the various possible causes of complex pathologies, usually characterized by long courses of rehabilitation $(28,29)$.

The results of the tests administered support the initial assumptions (Tab. 1). Intermediate scores are considered "not interesting" because they are different from very high or very low scores, which are conside- 
Table 1 . The first results of the experimental tests administrations.

\begin{tabular}{|c|c|c|c|c|c|c|}
\hline TEST & $\begin{array}{l}\text { AD } \\
\text { MI } \\
\text { N. } \\
\mathbf{N}^{\circ}\end{array}$ & $\begin{array}{l}\text { PATIENTS } \\
\text { TYPOLOGY }\end{array}$ & $\begin{array}{l}\text { TO BE IMPROVED DURING THE } \\
\text { COACHING COURSE }\end{array}$ & $\begin{array}{l}\text { N. of } \\
\text { patients } \\
\text { with } \\
\text { interesting } \\
\text { scores } \\
\text { (sportsmen) }\end{array}$ & $\begin{array}{l}\text { N. of } \\
\text { patients } \\
\text { with } \\
\text { interesting } \\
\text { scores } \\
\text { (not } \\
\text { sportsmen) }\end{array}$ & $\begin{array}{l}\text { N. of } \\
\text { patients } \\
\text { without } \\
\text { interesting } \\
\text { scores }\end{array}$ \\
\hline TSK & 13 & $\begin{array}{l}\text { Sportsmen n. } 7 \\
\text { Not sportsmen n. } 6\end{array}$ & $\begin{array}{l}\text {-High fear of movement } \\
\text {-High fear of pain }\end{array}$ & $\begin{array}{l}2 \\
4\end{array}$ & $\begin{array}{l}4 \\
5\end{array}$ & $\begin{array}{l}7 \\
4 \\
\end{array}$ \\
\hline $\begin{array}{l}\text { EMOTIONAL } \\
\text { INTERVIEW } \\
\text { TEST }\end{array}$ & 13 & $\begin{array}{l}\text { Sportsmen n. } 7 \\
\text { Not sportsmen n. } 6\end{array}$ & $\begin{array}{l}\text {-Poor contact with body } \\
\text {-Poor recognition of emotions } \\
\text {-High sense of personal responsibility } \\
\text {-Negative view of rehabilitation pathway } \\
\text {-Interest in emotional coaching course }\end{array}$ & $\begin{array}{l}6 \\
6 \\
6 \\
4 \\
5\end{array}$ & $\begin{array}{l}6 \\
6 \\
4 \\
6 \\
6\end{array}$ & $\begin{array}{l}1 \\
1 \\
3 \\
3 \\
2\end{array}$ \\
\hline $\begin{array}{l}\text { PREVIOUS } \\
\text { RE-INJURY } \\
\text { TEST }\end{array}$ & 7 & Sportsmen n. 7 & $\begin{array}{l}\text {-Presence of social and family prejudices } \\
\text {-High motivation for professional success } \\
\text {-High competition stress } \\
\text {-Poor decisional capacity } \\
\text {-Poor prefiguration of the future }\end{array}$ & $\begin{array}{l}5 \\
6 \\
6 \\
4 \\
5 \\
5\end{array}$ & $\begin{array}{l}- \\
- \\
-\end{array}$ & $\begin{array}{l}2 \\
1 \\
3 \\
3 \\
2 \\
2\end{array}$ \\
\hline $\begin{array}{l}\text { FORMATIVE } \\
\text { CONTRACT }\end{array}$ & 13 & $\begin{array}{l}\text { Sportsmen n. } 7 \\
\text { Not sportsmen n. } 6\end{array}$ & $\begin{array}{l}\text {-Communicative incoherence } \\
\text {-Poor clearness of rehabilitation goals } \\
\text {-Changes in rehabilitation goals during the course }\end{array}$ & $\begin{array}{l}3 \\
4 \\
4\end{array}$ & $\begin{array}{l}5 \\
6 \\
6\end{array}$ & $\begin{array}{l}5 \\
3 \\
3\end{array}$ \\
\hline
\end{tabular}

red "risk factors" for some pathologies or diseases, i.e. phobic behaviors, several forms of depression or somatizations, overuse of drugs, re-injury or withdrawal from any sport activities.

The test results show that, for healthcare operators, it is a duty to support patients and athletes in order to prevent the development of such pathologies.

Thus, the test scores may be seen as goals to be targeted or elements to be developed during the physical rehabilitation pathway and a possible emotional coaching course.

\section{Pathological and authentic forms of communication}

According to the transactional analysis theory, through the above-mentioned quantitative and qualitative tools, the operator is able to protect the boundaries of his professional role, and this allows him to be powerful, not only in a technical but also in a welcoming sense (30).

In fact, the "tests", the "contract training" and "talks" are useful tools for protecting both the operator and the patient from the risk of engaging in a pathological form of communication, which is very widespread and insidious: the "Game" (30). This is common in every social, work and family setting. It is activated by the participants (a minimum of two), unconsciously and involuntarily, as a means of satisfying their own deep and personal needs. One of the primary needs in every person is to receive "stimula" or "strokes". Often, this need is so urgent that it matters little to the individual whether what he receives are positive or negative, warm or devaluing strokes (31).

The basic structure of the "game" is called the "drama triangle" (Fig. 6). Each of the participants plays, for longer or shorter periods, the roles corresponding to the three vertices of the triangle: "savior", "persecutor", and "victim".

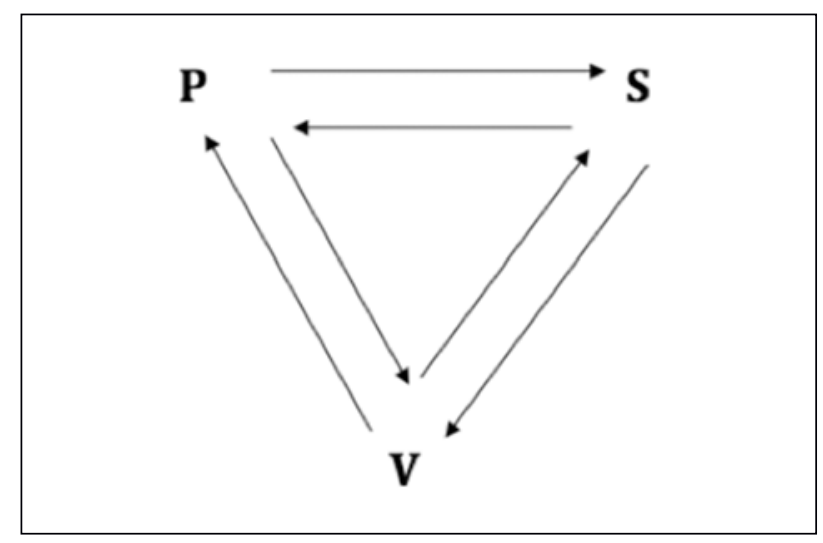

Fig. 6. THE DRAMA TRIANGLE

The diagram shows the basic structure of the "game", which is a pathological form of communication in the care relationship. 
Usually, in the healthcare setting, the operator plays the role of savior and/or persecutor, while the patient plays the victim and/or persecutor. Each change of role, called "switch", is unconscious and causes, in all the players, an unexplained discomfort that leads to expressions of anger, resentment, detachment.

The savior's role is usually regarded as initially beneficial; he may be an authoritative, competent, friendly person but, during the course of the rehabilitation process, he tends unconsciously to underestimate the healing abilities of the patient, who entrusts to him every decision and project.

The persecutor can be a figure similar to, but more authoritarian and severe, than the previous one, who sees the patient as a number or a problem to be solved in the shortest possible time. In reality, in both these cases, the operator tends to be gratified by the power he has over the patient and by his ability to maintain the patient in a perpetual state of need and dependence.

The patient, at the same time, plays the part of the victim, delegating all decisions to the healthcare operator. He hopes to please the doctor and enjoys this period of apparent mental and physical "inability" as a "holiday". In the short or medium term, communication and relationships of this kind, called "symbiotic", may have some utility; however, in the long run, they create a deep dependence, which is damaging both to the operator's self-esteem and to the patient's autonomy.

In fact, it is often the victim who flicks the "switch" and changes his role, assuming that of the persecutor, sometimes becoming an angry avenger against the whole healthcare facility. The resentment, which builds up over time in the various players, can be expressed in unpredictable ways. Thus, "games", in extreme cases, can end up being resolved in the law court.

To recognize, exit or make positive use of the communicative "games" typical of a care relationship, it is useful (although not easy) to stimulate awareness in each operator of how some communication forms may be ineffective or even harmful to the final outcome of the course of rehabilitation.

In conclusion, we recall an ancient medical and philosophical principle, the "physis", asserted by Heraclitus and often referred to, in the history of thought, until Freud and Berne, namely that there exists a deep human instinct to live and to heal. The impulse towards well-being seems strong enough to push humans to "integrate", within themselves, body, emotions, reason, memories and behaviors into a harmonious whole, original and useful for survival. Thus, Berne's "integrated adult" recalls the "authentic human being" of Heidegger and of Existentialism. We feel that it is important that in Italy, as elsewhere, physical and sport rehabilitation pathways in accordance with these considerations be proposed, so as to offer both patients and operators an opportunity to "integrate" not only techniques but also emotive, cognitive, communicative and relational skills.

\section{References}

1. Nuttall J. The existential phenomenology of transactional analysis. Transactional Analysis Journal. 2006;36:214-227.

2. Heidegger M. Being and Time. New York, State University of New York Press, 1996.

3. Binswanger L. Existence: A New Dimension in Psychiatry and Psychology. New York, Basic Books, 1958.

4. Berne E. Transactional Analysis in Psychotherapy. New York, Grove Press, 1961.

5. Erskine R, Zalcman MJ. The racket system: a model for racket analysis. Transactional Analysis Journal. 1979;9:51-59.

6. Allen JR. The experienced self as a developmental line and its script work. Transactional Analysis Journal. 2011;41:58-68.

7. Thomson G. Fear, anger and sadness. Transactional Analysis Journal. 1983;13:20-24.

8. Cornell WF, Hine J. Cognitive and social functions of emotions: a model for transactional analysis counselor training. Transactional Analysis Journal. 1999;29:175-185.

9. Trevarthen C. The Neurobiology of Early Communication: Intersubjective Regulations in Human Brain Development. Dordrecht, Kluwer, 2001.

10. English F. The three cornered contract. Transactional Analysis Journal. 1975;4:383-384.

11. Kori SH, Miller RP. Kinesophobia: a new view of chronic pain behaviour. Pain Management. 1990;3:35-43.

12. Lundberg MKE. A psychometric evaluation of the Tampa Scale for Kinesiophobia from a physiotherapeutic perspective. Physiotherapy and Practice. 2004;20:121-133.

13. Woby S, Roach NK, Urmston M, et al. Psychometric properties of the TSK-11: a shortened version of the Tampa Scale for Kinesiophobia. Pain. 2005;117:137-144.

14. Malterud K. Qualitative research: standards, challenges and guidelines. Lancet. 2001;358:483-488.

15. Mann BJ, Grana W, Indelicato P, et al. A survey of sports medicine physicians regarding psychological issues in patientathletes. Am J Sports Med. 2007;35:2140-2147.

16. Pally R. Emotional processing: the mind-body connection. Int J Psychoanal. 1998;79:349-362.

17. Wiese-bjornstal DM, Smith AM, Shaffer SM, et al. An integrated model of response to sport injury: psychological and sociological dynamics. Journal of Applied Sport Psychology. 1998;10:46-69.

18. Heil J. Psychology of Sport Injury. Champaign, IL, USA, Human Kinetics Publishers,1993. 


\section{oints}

19. Griffin LY, Agel J, Albohm MJ, et al. Noncontact anterior cruciate ligament injuries: risk factors and prevention strategies. J Am Acad Orthop Surg. 2000;8:141-150.

20. Tjong VK, Murnaghan ML, Nyhof-Young JM, et al. A qualitative investigation of the decision to return to sport after anterior cruciate ligament reconstruction: to play or not to play. Am J Sports Med. 2014;42:336-342.

21. Ryan RM, Deci EL. Self-determination theory and the facilitation of intrinsic motivation, social development and wellbeing. Am Psychol. 2000;55:68-78.

22. Brophy RH, Schmitz L, Wright RW, et al. Return to play and future ACL injury risk after ACL reconstruction in soccer athletes from the Multicenter Orthopaedic Outcome Network (MOON) Group. Am J Sports Med. 2012;40:25172522

23. Chmielwski T, Jones D, Day T, et al. The association of pain and fear of movement/reinjury with function during ACL reconstruction rehabilitation. J Orthop Sports Phys Ther. 2008;38:746-753.

24. Kvist J, Ek A, Spornstedt K, et al. Fear of re-injury: a hin- drance for returning to sports after ACL reconstruction. Knee Surg Sports Traumatol Arthrosc. 2005;13:393-397.

25. Langford JL, Webster KE, Feller JA. A prospective longitudinal study to assess psychological changes following ACL reconstruction surgery. Br J Sports Med. 2009;43:377-378.

26. Tripp D, Stanish W, Ebel-Lam A, et al. Fear of reinjury, negative affect and catastrophizing predicting return to sport in recreational athletes with ACL injuries at 1 year post surgery. Sport Exerc Perform Psychol. 2011;1:38-48.

27. Chase M, Magyar M, Drake B, et al. Fear of injury in gymnastics: self-efficacy and psychological strategies to keep on tumbling. J Sports Sci. 2005;23:465-475.

28. Burton KA, Tillotson KM, Main CJ, et al. Psychological predictors of outcome in acute and sub chronic low back trouble. Spine. 1995;20:722-728.

29. Butler DS, Moseley LS. Explain Pain. Adelaide, South Australia, Noigroup Publications, 2003.

30. Berne E. Games People Play. Grove Press, New York, 1964.

31. Steiner C. The stroke economy. Transactional Analysis Journal. 1971;1:9-15. 